\title{
BREVE RESEÑA SOBRE LA OBRA DE FREGE
}

\author{
A. Gonzalo - D. Attala
}

Los símbolos tienen para el pensar la misma importancia que para la navegación tiene la ocurrencia de usar el viento para navegar a contra viento.

$$
\text { G. Frege. }
$$

\section{I.- Programa y desarrollo del pensamiento de Frege}

Gottlob Frege nació en 1848 y murió en 1925. Su carrera profesional de matemático y filósofo transcurrió en el departamento de matemáticas de la Universidad de Jena. Poco conocido durante su vida (como no lo fueran las obras de Husserl, Russell, o Wittgenstein quienes, por otro lado, apreciaron y estudiaron la de Frege), su trabajo es considerado actualmente de fundamental importancia en las áreas a las que dedicó su atención: filosofía de la matemática, lógica y filosofía del lenguaje (o semántica filosófica).

Siguiendo a Dummett (1), la carrera intelectual de Frege puede ser dividida en cinco períodos bien delimitados. El primero comprende la publicación de la Conceptografía (2) (Begriffsschrift, de ahora en más, BS) (1879) y de algunos artículos destinados a explicarla o justificarla. Parte de las ideas básicas del programa que Frege intentará desarrollar a lo largo de la mayor parte de su obra están ya señaladas concisamente en el prologo de aquella. Allí Frege sostiene que si se desea responder a la pregunta sobre el modo de fundamentar una proposición debe tenerse en cuenta la naturaleza interna de la misma y, aunque sin referirse directamente a dicha naturaleza, Frege divide en

(1) "La filosofía de Frege", en M. Dummett, La verdad y otros enigmas, ed. F.C.E., México, 1990, pp. 159-162.

(2) Las citas de este texto están sacadas de la traducción de H. Padilla, Conceptografía, que incluye también Los fundamentos de la aritmética y Otros estudios filosóficos, ed. UNAM, Méxion, 1972. 
dos las clases de verdades que requieren una fundamentación: una, la de aquellas proposiciones cuya verdad se establece por medio de una "prueba puramente lógica" (3); otra, la de aquellas cuya verdad se basa en 'hechos empíricos'. Es importante que dicha clasificación no toma en cuenta el origen psicológico de las proposiciones (es decir, el proceso por el que alguien llega a formularlas) sino sólo su modo peculiar de justificación (4). Ahora bien, la preocupación central de Frege es la de saber a cuál de estas dos clases pertenecen los juicios de la matemática, y su intento en relación a esta preocupación es ver hasta dónde es posible llegar en la aritmética (5) exclusivamente por medio de inferencias basadas únicamente en leyes lógicas.

Para ello Frege se propone seguir el procedimiento de "retrotraer el concepto de ordenación en una serie al de consecuencia lógica y de aquí progresar hasta el concepto de número" (BS, p. 8). Pero para que este proceso fuera puramente lógico era necesario evitar en todo momento la intromisión explícita o subrepticia de un ingrediente que Frege consideraba completamente ajeno a la lógica (y ligado, en cambio, a la experiencia sensible): la intuición. Esta no debía tener ningún papel en la evaluación de las inferencias, y la única garantía de que esto no ocurriera era la supresión de toda laguna en la cadena formada por ellas, tarea impensable, para Frege, con los medios ex-

(3) Qué deba entenderse aquí por "lógica" es una cuestión difícil. En el texto que comentamos Frege caracteriza las leyes lógicas como aquellas leyes del pensamiento que prescinden de todas las particularidades de aquello a lo que estas leyes se aplican.

(4) Esta distinción entre el origen psicológico y el modo como se justifican las verdades, recuerda muy de cerca a la kantiana entre el comienzo "en" la experiencia de todos nuestros conocimientos, y la no procedencia de todos ellos "de" la experiencia I. Kant, Crítica de la razón pura.

(5) El interés por la aritmética se entiende en el contexto del desarrollo teórico del siglo XIX conocido como "aritmetización de la matemática" "que redujo toda la ciencia a una larga cadena de deducciones y construcciones, a partir del número natural", J. Rey Pastor y otros, Análisis Matemático, ed. Kapeluz, Buenos Aires, 1969 , p. 11. "En líneas generales, se llegó a mostrar que numeros de ciertas categorías se podían interpretar como determinados conjuntos construidos a partir de números de otras categorías", Orayen, La ontología de Frege, Universidad Nacional de La Plata, 1972, cuad. 3, p. 10. 
presivos con que contaba. Estas razones lo llevan a elaborar un lenguaje de fórmulas (su conceptografía) que le permitiría "probar de la manera más segura la precisión de una cadena de inferencias" y "denunciar toda proposición que quisiera colarse inadvertidamente y poder investigarla en su origen" (BS, p. 8).

Pero no sólo le preocupa a Frege la aplicación de su conceptografía al campo de la aritmética (aunque sea ese el campo al que dedicara la mayor parte de sus esfuerzos). Otro punto se hace necesario señalar y es que Frege consideraba, situándose en la línea del programa leibniziano de elaborar un calculus philosophicus o raciocinator, que un lenguaje como el de su conceptografía abría "las más amplias perspectivas para llenar las lagunas de los lenguajes existentes, para conectar en un sólo dominio campos separados hasta ahora y para ampliarse a campos en los que tal lenguaje faltaba" (BS, p. 9). Así, consideraba posible la aplicación de su lenguaje al cálculo diferencial e integral, a la geometría (completándolo con símbolos para la expresión de las relaciones intuitivas peculiares), a la teoría del movimiento puro, a la mecánica, a la física (en estos tres últimos ítems, adecuando el simbolismo al progreso del conocimiento), y a la filosofía. Por último, Frege considera de especial importancia su conceptografía para la lógica (ver infra, 2).

El objetivo de Frege era, después de la elaboración de su lenguaje, aplicar su programa a la aritmética, y habiendo adelantado algo de ello en BS, la tarea más importante era presentar la aritmética como una teoría axiomática. En este punto Frege propuso su tesis, conocida como 'tesis logicista', de que las nociones y las leyes fundamentales de la aritmética pueden reducirse a nociones y principios puramente lógicos (6). La exposición preliminar de esta posición nos lleva a una segunda etapa en la obra de Frege, período que comprende hasta la publicación de la obra más netamente filosófica, sus Fundamentos de la aritmética (Die Grundlagen der Arithmetik, de ahora en más GA).

(6) Es de destacar que ésto Frege lo consideraba posible sólo para el análisis (la teoría de los números reales) y la aritmética elemental, no así para la geometría, para la que siempre tuvo por válida la posición kantiana de considerarla fundada en juicios sintéticos a priori (no reductibles a la lógica). 
Allí Frege se aboca a criticar detalladamente los puntos de vista de sus contemporáneos a través del diálogo crítico con el de sus predecesores, especialmente Kant y Stuart Mill. Los formalistas, sin antecedentes históricos tan relevantes como estos, son atacados directamente. El análisis de estos autores gira alrededor de las dos cuestiones en que Frege está interesado aquí, a saber, la naturaleza de las proposiciones matemáticas y la naturaleza del número. En contraposición a éstos, seguidamente, esbozó su propio método para definir las nociones básicas de la aritmética (especialmente la de número) en términos de nociones puramente lógicas, y probar que las leyes fundamentales de la aritmética pueden inferirse de principios puramente 16gicos (aclarando así la cuestión de la naturaleza de las verdades matemáticas). Es aquí, en una investigación fronteriza entre la matemática y la filosofía, donde Ferge formula claramente ciertas ideas filosóficas acerca del lenguaje y de los significados que lo llevarán de allí en adelante a seguir profundizando en la elaboración de lo que se conoce como su semántica filosófica, destinada a solucionar los escollos hallados en el desarrollo de su tesis acerca de la matemática (7).

El tercer período llega hasta la publicación del segundo volumen de Las leyes fundamentales de la aritmética (Die Grundgesetze der Arithmetik). Sus ideas acerca del lenguaje cobran en esta época toda su importancia; ellas son expuestas en forma dispersa en el primer volumen de los Grundgesetze (1893), pero fueron sistemáticamente expuestas en tres obras publicadas entre 1891 y 1892, Función y concepto, Sobre sentido y referencia, y Sobre concepto y objeto (8), y en el segundo volumen de los Grundgesetze. Los problemas (y sus soluciones) expuestos en estas obras impregnan la mayor parte de la filosofía del lenguaje contemporánea. Por otro lado, en los Grundgesetze

(7) La mayoría de los críticos consideran que la semántica fregeana surge en orden a problemas de la filosufía de la matemática de Frege. Ver, por ejemplo, Orayen, op. cit., pp. 9-10 y, del mismo autor, "Frege: una aproximacion a sus concepciones semánticas", Rev. Ergo, vol. II, agosto 1988, p. 14.

(8) Funktion und Begriff, Über Sinn und Bedeutun y Über Begriff und Gegenstand, las traducciones de estos textos, junto a otros del mismo tenor, en Estudios sobre semántica, ed. Orbis, Bs. As., 1985. 
Frege aborda la realización del proyecto de los GA (de deducir las leyes y las nociones de la aritmética -y, en el segundo volumen, del análisis- a partir de otras de carácter puramente lógico), sólo que variando el número de reglas de inferencia y de axiomas e introduciendo una teoría intuitiva de conjuntos (9).

No se sabe a ciencia cierta lo sucedido a Frege durante el cuarto período -1904/1917- ya que Dummett, quien ha tenido acceso a sus escritos inéditos, sólo aventura la hipótesis -que los comentaristas repitende una "profunda depresión", posiblemente debida a la escasa repercusión de su obra en sus contemporáneos. De todos modos, en esta época Frege publica algunos escritos de carácter sólo polémico o programático.

En 1918, quinto período, Frege comienza la publicación de una serie de tres artículos -proyectados al principio como partes de un libro de lógica filosófica- que aparecen entre esa fecha y 1923. Ellos son El Pensamiento. Una investigación lógica, La negación. Una investigación lógica e Investigación lógica. Tercera Parte: composición de pensamientos (10). En gran parte estos escritos de lógica filosófica están motivados por la introducción ilegítima de nociones psicológicas sufrida por la lógica en época de Frege, y por el deseo de Frege por impedir "que se borrase la frontera entre la lógica y la psicología" (11). Desde antes de mediados del siglo XIX en Alemania venía tomando cada vez más fuerza una posición filosófica conocida luego como naturalismo. La misma, aplicada a la lógica, se transforma en psicologismo, en una concepción de la lógica en términos de ciencia de los procesos involucrados en ciertas operaciones de la mente. Es contra esta idea que Frege elabora su postura sobre lógica filosófica y, aunque esto ya venía haciéndolo Frege desde sus GA, en estos

(9) Será justamente en el seno de esta teoría donde B. Russell hallará la conocida paradoja que, a pesar de las modificaciones hechas por Frege al efecto, dará por tierra con gran parte de su construoción.

(10) Der Gedanke, Eine logische Untersuchung, Die Verneinung. Eine logische Untersuchung i Logische Untersuchung. Dritter Teil: Gedankengefüge, respectivamente, cuyas traducciones están e.l Investisgaciones lógicas, ed. Tecnos, Madrid, 1988.

(11) Investigaciones lógicas, p. 50. 
escritos se vuelve a ocupar de estas cuestiones extensamente. Esto ocurre especialmente en El Pensamiento, estudio en el cual Frege intenta (con un resultado no muy convincente), mostrar el objeto de la lógica como ciencia. Siendo la palabra "verdadero" la que señala dicho dominio, el mismo queda acotado mediante lo que Frege llama -y cuyo alcance procura delimitar en el ensayo- "las leyes del ser verdad". En este intento, por otro lado, es donde Frege expone de la manera más cruda (como jamás lo había hecho) su posición realista platónica, es decir, su concepción de que aquello que es verdadero o falso y que Frege llama "pensamiento" existe en un tercer reino, distinto del primero -la realidad material- y del segundo -las representaciones subjetivas individuales de las personas-. Dicho tercer reino puede ser captado por los hombres, quienes pueden juzgar acerca de la verdad o falsedad de los pensamientos; pero de ningún modo puede ser creado por los hombres, es enteramente independiente de ellos, y tanto, que Frege dice del mismo que es atemporal e inmutable.

En el ensayo sobre la negación -ciertamente el mejor logrado de los tres-, Frege procura mostrar, como un intento de apoyar su tesis sobre la "subsistencia del pensamiento" (con independencia de la captación de los hombres), que el acto de juzgar nada tiene que ver con la "composición" del contenido judicativo. Según Frege, si se admite la posición que ve en el juicio una composición de partes separadas cuya autoría recae en el sujeto que juzga -por ejemplo, algo del estilo de la teoría kantiana del juicio- se hace imposible sostener aquella tesis (de que los contenidos judicativos no son creación de los hombres sino que ya están dados y los hombres lo único que hacen es captarlos y darles o no asentimiento), por el contrario, si se logra separar el acto de juzgar del contenido judicativo, se torna plausible al menos dicha tesis. Frege intenta lograr su objetivo al hilo de una investigación sobre el "sentido" de las oraciones interrogativas y sobre la supuesta tajante diferencia -que, según Frege, no es tal- entre juicios negativos y afirmativos. Por último, en Composición de pensamientos continúa con el intento de cimentar la tesis que comentamos ahora, a partir de un esfuerzo por mostrar los modos en que los pensamientos pueden 
componerse a partir de otros; esto lo hace Frege haciendo una tabla de seis maneras de operar dicha composición. En este ensayo Frege parte del supuesto -siempre presente en todas sus obras- de que a las expresiones del lenguaje le corresponder entidades no perceptibles situadas en ese mundo del que habla en El Pensamiento. Así, junto con la clasificación de los modos de componer, indica la composición de expresiones lingüísticas que deben corresponder a la de pensamientos. El saldo que de esto pretende extraer Frege parece ser que si la composición de pensamientos se explica por la sola puesta en relación de pensamientos preexisientes completos, la actividad subjetiva de quien juzga no tiene el más mínimo papel. El sujeto humano -"terrícola" llega a decir Frege- se limita a captar dicha composición, que ya está efectuada desde siempre en el reino de los pensamientos puros. Dice Frege al comienzo de Composición..., en una nota: "Aquí, y en lo que sigue, no debe perderse de vista que este saturar, este componer no es ningún proceso temporal" (12). Luego intenta mostrar que cada uno de los seis modos de componer tomados aisladamente, junto a la negación, pueden servir para derivar los cinco restantes. Finalmente, formula la hipótesis, de claro espíritu leibniziano, de que tal vez todas las ciencias utilicen pensamientos cuya composición sea la misma que la de los pensamientos propios de la matemática $\mathrm{y}$, especialmente, de la lógica; mas deja esta cuestión sin decidir.

Sin embargo, hacia 1923 Frege había desistido de su proyecto logicista; las paradojas en el seno de su teoría de conjuntos lo habían llevado a ello. Según Dummett, Frege cambia finalmente por esta época su estrategia de fundamentar la aritmética en la lógica y comienza a considerar a la geometría como disciplina fundamental dentro de la matemática y a esta, por ende, compuesta de verdades sintéticas $a$ priori. Y, a pesar de que sobre esta última perspectiva sobre la matemática Frege no llegó a publicar nada, en las tres investigaciones lógicas mencionadas el cambio en los intereses de Frege se expresa indirectamente de muchos modos (por ejemplo, aún cuando sea un

(12) Investigaciones lógicıs, p. 115, nota. 
rasgo por sí sólo superficial, hay en estos textos una ausencia casi total de formalismos lógicos).

\section{II.- La lógica del begriffsschrift}

Begriffsschrift (Ideografía o Conceptografía) constituye el primer tratado sistemático de lógica matemática y, por ésto, muchos autores estiman 1879, año de su publicación, como año del surgimiento de la lógica formal. En esta obra se realiza la formulación del cálculo clásico de predicados de segundo orden, cuyo fragmento de primer orden constituye una formalización completa de la lógica de primer orden (y de hecho, cuyo fragmento oracional constituye la primera formalización completa, a la manera moderna, de la lógica clásica de oraciones).

En esta obra se elabora por primera vez una teoría de la cuantificación y se establecen reglas de su uso, se introduce la noción de función lógica, y se distingue entre función de uno o varios argumentos, se implementa el uso de variables y constantes y, además, se enuncia qué es un sistema lógico deductivo y se realiza una exposición de dicho sistema. La mayoría de estas nociones se difundieron a través de los Principia Mathematica de Whitehead y Russell (1911), en donde con aportes de otros lógicos contemporáneos a Frege, la lógica matemática adquirió cierta estandarización tanto nocional como notacional.

BS surge como necesidad de construcción de un lenguaje formal y un aparato deductivo que permitiera contar con herramientas sólidas para cumplir con el programa logicista de fundamentación de la aritmética, tarea que se proseguiría en obras posteriores. Sólo que desde esta primera obra Frege se verá necesitado de introducir cuestiones que lo conducirán a planteos de filosofía del lenguaje o semántica filosófica por un lado, y de filosofía de la matemática por otro.

Dada la "revolución lógica" que BS provocó vamos a introducir aquí algunos comentarios del sistema lógico presentado allí por Frege, pero antes nos parece necesario acotar que la construcción del lenguaje lógico y el aparato deductivo de BS están en parte motivados por el 
rechazo de Frege, I) de la ambigüedad e imprecisión del lenguaje ordinario y sus insuficiencias para la "expresión del pensamiento puro"; II) de la estructuración gramatical trasladada al lenguaje de la lógica tradicional; III) del psicologismo, o de toda introducción de aspectos mentales en lógica; y podríamos agregar, IV) del formalismo, o concepción de la lógica como un mero sistema de cálculo formal.

I) Frege a menudo se pronunció sobre las insuficiencias de los lenguajes naturales, pensaba que no sólo son un instrumento precario para la expresión del pensamiento sino que los lenguajes naturales son además incoherentes dado que no podría lograrse una explicación sistemática completa del uso de las oraciones de estos lenguajes. Como hace notar Dummett (13), esta observación acerca del lenguaje natural es común a otros filósofos contemporáneos a él, sólo que Frege discrepó de ellos en el remedio metodológico que adoptó. La vía seguida por Frege para intentar solucionar el carácter equívoco e insatisfactorio de nuestros lenguajes cotidianos fue reemplazarlos, para propósitos científicos y filosóficos, por formas lingüísticas que no tuvieran estos defectos. Se debían desarrollar primero medios mejores para expresar el pensamiento $y$, después, formular de modo adecuado y explícito los principios que gobiernan el empleo de estas formas de expresión. Para conseguir estos fines dedica su atención a construir un lenguaje de fórmulas que, según su propia expresión, sería al hablar ordinario "como el ojo al microscopio".

II) Así, Frege postula que una de las tareas de la filosofía debe consistir en liberar al espíritu humano de los errores a los que conduce el lenguaje ordinario: "liberar al pensamiento de aquellos engaños con que lo plaga la naturaleza de los medios lingüísticos de expresión" (14). En particular debía eliminarse de un lenguaje lógico la confusa terminología de "sujeto" y "predicado". La diferencia entre "los grie-

(13) "La Distinción fregeana entre el sentido y la referencia", en M. Dummett $L a$ Verdad y otros Enigmas. F.C.E.

(14) Frege, G. Prólogo a "Conceptografia". 
gos vencieron a los persas en Platea" y "los persas fueron vencidos por los griegos en Platea" es irrelevante para la lógica, ya que presentan el mismo pensamiento o contenido conceptual, y uno de los dos enunciados podría ser indistintamente reemplazado por el otro a título de premisa sin que ello afecte la validez de nuestros procesos deductivos, y es precisamente dicha validez lo que interesa a Frege en la elaboración del lenguaje lógico. Imaginemos un lenguaje en el que la totalidad del contenido de un juicio podría expresarse por una cláusula sujeto, como por ejemplo en la expresión "La muerte violenta de Arquímedes en la batalla de Siracusa es un hecho"; en esta forma de expresión sólo habría una y la misma cláusula predicado para todos los enunciados, a saber, "es un hecho", pero esta cláusula no se asemejaría a las cláusulas predicativas ordinarias, ya que su único cometido sería contribuir a la presentación del contenido que oficia de sujeto en la forma de un juicio. Es un lenguaje de este tipo el que Frege propone en sustitución de aquellos que mantienen la distinción tradicional entre sujeto y predicado. Frege pensaba, quizá acertadamente, que la sustitución de los conceptos de sujeto y predicado por los de argumento y función se acreditaría con el tiempo.

III) y IV) El objetivo fundamental de Frege al desarrollar este sistema lógico era alcanzar el ideal de rigor al cual aspiraban todos los matemáticos del siglo XIX; si las pruebas se formalizaban de manera completa, entonces no sería necesario apelar a la intuición al evaluar la corrección de una prueba y, por tanto, habría por fin una certeza de que las pruebas eran concluyentes y estaban fundadas sólo en procedimientos puramente lógicos.

Pero este ideal de rigor lógico va a desarrollarse de la mano de una determinada semántica filosófica que determinará que la ideografía no se conciba meramente como la búsqueda de un simbolismo más o menos arbitrario, y la construcción de un cálculo formal que permitiera ulteriores interpretaciones diversas. El lenguaje lógico presentado no consiste en un conjunto de fórmulas al que arbitrariamente se le asignarán determinados significados, sino que para Frege el signo 
es inseparable del contenido conceptual que representa o conlleva (15). Y ese contenido conceptual (que es para Frege un pensamiento puro, en el sentido de que es independiente de que el sujeto lo perciba, lo imagine, lo piense) es un "contenido objetivo" que requiere de un instrumento apropiado para su expresión (16). Esta concepción de la prioridad del contenido conceptual sobre el signo que lo expresa marcará justamente su enfrentamiento al procedimiento booleano de la construcción del cálculo lógico, considerando que tales cálculos, por su punto de partida, se mostrarán impotentes para la expresión precisamente de los conceptos y relaciones estrictamente lógicos. Este mismo punto explica su polémica con Hilbert, en la que Frege se negó a admitir el método axiomático formal.

BS no pretende ser un mero cálculo lógico, sino justamente una conceptografía, un sistema que permita la traducción a signos que reflejen las relaciones entre los contenidos conceptuales simbolizados, mediante reglas estrictamente especificadas.

Pasemos a considerar ahora algunas nociones centrales de la Conceptografía. En los primeros parágrafos de ésta se distinguen: "expresión", "contenido judicativo" de esa expresión y "aserción" o "juicio" del contenido judicativo (o pensamiento). Para diferenciar claramente estos aspectos se diseña un simbolismo lógico: la expresión del contenido de juicio se representa por una letra gótica -aquí usaremos en reemplazo letras latinas mayúsculas-, tomemos $\mathbf{A}$. El contenido del juicio se representa por una barra horizontal:

(15) Como posteriorments precisará, una proposición lógica no es más que un signo compuesto según una regla determinada; signo que posee un "sentido" que mantendrá en cualquier lengua a la que se traduzca. Frege llamará al sentido de un enunciado "pensamiento" y lo concebirá como una entidad independiente de la actividad psicológica subjetiva.

(16) Esta concepción se ha venido a denominar su "platonismo": el sujeto no crea los conceptos, los aprehende; como tampoco se crean los pensamientos de que trata la matemática, sino que se develan. Un ejemplo que Frege expone es que el pensamiento que se tiene del teorema de Pitágoras es el mismo para todo ser humano y su verdad es independiente de que sea o deje de ser pensado por algún individuo determinado. 
que Frege denomina "trazo de contenido", que indica un pensamiento en el cual aún no se reconoce juicio alguno acerca de la verdad de dicho pensamiento; y aserción del contenido o juicio, que se expresa simbólicamente colocando una barra vertical en el extremo izquierdo de la horizontal, que denominamos "trazo del juicio"; nos queda, pues, simbolizado:

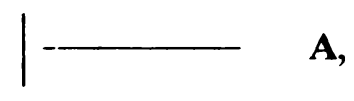

que significa que A tiene lugar o que es un hecho.

Así como la distinción sujeto-predicado es de carácter gramatical, Frege considera que también lo es la distinción comúnmente establecida entre juicios categóricos, hipotéticos y disyuntivos. Las distinciones modales, por otro lado, podrán ser ignoradas por referirse simplemente al fundamento cognoscitivo de nuestros juicios más que al contenido lógico de los mismos.

Se introducen a continuación en el sistema las constantes lógicas primitivas: cuantificador universal, e identidad de contenido entre signos; además de las conectivas condicional y negación. La conceptografía abarcará en un primer apartado la descripción semántica de estas constantes lógicas, con las que se elabora un sistema de lógica proposicional y lógica de predicados con identidad; y en uno segundo, se enunciarán los axiomas y reglas del sistema.

El condicional se representa por un trazo vertical que afecta al trazo de contenido judicativo y está trabajado de manera veritativo-funcional al modo del condicional filónico. El mismo se representa en el esquema: 


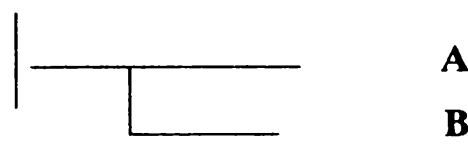

que expresa la exclusión del caso "A es negado y B afirmado", mientras que se admite la posibilidad de los otros tres casos. (La escritura fregeana del condicional obliga a que el antecedente se escriba debajo y el consecuente arriba).

La negación es caracterizada del siguiente modo: "si un pequeño trazo vertical se liga por debajo a la línea de contenido, se expresará la circunstancia de que el contenido no tiene lugar", así:

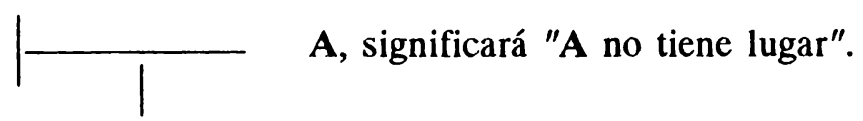

La combinación del condicional y de la negación permite definir las restantes conectivas proposicionales: la conjunción y la disyunción, de la que Frege sólo manejará su sentido no excluyente.

Descriptas las conectivas básicas de la lógica proposicional, se pasa a la introducción semántica de la teorías de la cuantificación con identidad. La identidad se introduce como un predicado de dos argumentos, introducción que constituye la primera definición de carácter estrictamente lógico de esta relación. Frege afirma: "La identidad de contenido se diferencia de la condicionalidad y negación en que se aplica a nombres y no a contenidos" (Parag. 8). La expresión significa "el signo A y el signo B tienen el mismo contenido conceptual, de forma que en lugar de $A$ se puede poner siempre $B$ y viceversa". (17)

$(\mathbf{A}=\mathbf{B})$

(17) Posteriormente a Begriffschrift se le presentarán a Frege ciertas dificultades que lo conducirán al abandono de la noción de "contenido", en favor de la elaboración de la distinción semántica de "sentido" y "referente". Distinción que le conduce a la posterior supresión de este tipo de igualdad en beneficio de la igualdad matemática. 
Para poder establecer la nueva constante lógica de generalidad, la cuantificación, Frege elabora lo que se considera uno de sus hallazgos centrales: el concepto de función. Para un uso inmediato llamaremos función a una "entidad predicativa no saturada" tal como "ser par", "ser más alto que", que representamos con una letra griega, seguida de uno o más lugares vacíos, que representamos con letras entre paréntesis como indeterminadas:

$$
\alpha(\mathbf{A}), \text { o } \beta(\mathbf{A}, \mathbf{B}),
$$

representando una función monádica y otra diádica respectivamente. Los términos que permitan cubrir un lugar vacío constituyen los argumentos de la función. Si al reemplazar convenientemente la letra entre paréntesis resulta que el contenido obtenido es capaz de ser aseverado y convertido en un juicio, entonces es que el argumento satisface la función; y esto es lo que expresa la aserción:

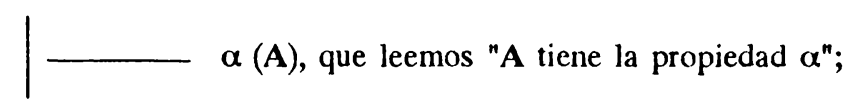

mientras que la aserción:

$\boldsymbol{\beta}(\mathbf{A}, \mathbf{B})$ puede leerse como "B está en relación $\beta$ con $\mathbf{A}^{\text {". }}$.

La introducción de la cuantificación universal establece uno de los logros más definitivos de la lógica matemática. La aserción: "todo cumple la propiedad a" se representa por:

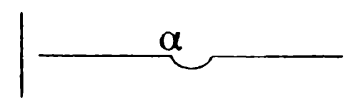

La cuantificación permite así distinguir entre variables ligadas (las que caen bajo el alcance del cuantificador) y variables libres y, 
determinar así el carácter proposicional de las expresiones con variables ligadas (dicho ésto en lenguaje contemporáneo).

Entre las reglas del cálculo proposicional, la única que aparece explicitada como regla de inferencia es la regla del modus ponens e, implícitamente, se opera con la de sustitución de variables y otras dos reglas para el cálculo de predicados, que conocemos hoy como reglas de introducción y de eliminación del cuantificador universal.

Para la presentación de su sistema Frege elige un total de nueve axiomas, cuya elección está presidida por el uso de cada una de las cuatro constantes lógicas primitivas. Frege no las explicita en bloque sino que va derivando de cada grupo de axiomas algunas consecuencias. Así, las fórmulas que enumera por (1), (2) y (8) constituyen los axiomas de condicionalidad; a ésta se agrega la negación y los axiomas que regulan ambas conectivas vienen dados por las fórmulas (28), (31) y (41). A estos se suman dos leyes más para la identidad, (52) y (54), ley de sustitución de la identidad y ley reflexiva de la identidad respectivamente.

Los axiomas citados, más las reglas, implican que dicho sistema de axiomas es "completo", en el sentido de completud de sistemas formales posterior (para la lógica de primer orden). Podríamos formularlos como sigue:
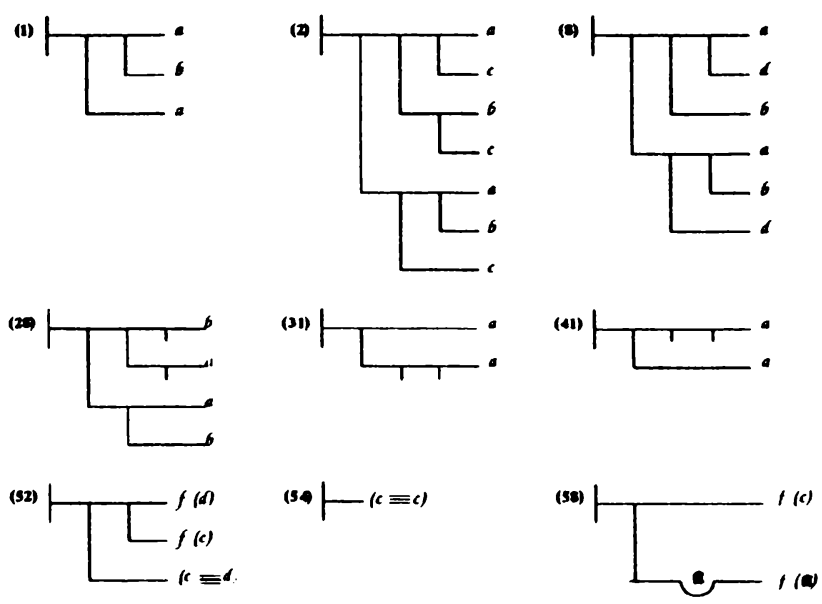


\section{III.- Las ideas semánticas}

Frege basó su investigación sobre la naturaleza de los números (expuesta en los GA) en tres principios fundamentales que tienen gran importancia por sus implicancias semánticas: I) "hay que separar tajantemente lo psicológico de lo lógico, lo subjetivo de lo objetivo"; II) "no se debe preguntar por el significado de una palabra aislada, sino en el contexto de una proposición"; y III) "hay que mantener siempre a la vista la diferencia entre concepto y objeto" (18).

I) El primer principio tiene la virtud de señalar que no deben tomarse en consideración, en una investigación sobre los significados, las imágenes mentales (subjetivas) que cada uno pueda tener en relación a un enunciado o una palabra. Estas imágenes mentales asociadas a los signos no pueden ser relevantes en ninguna empresa científica por cuanto están al abrigo de cualquier tipo de crítica, ya que son privativas de cada individuo y están sujetas a regularidades (deseos, necesidades, etc.) ajenas a las que exige la lógica (que sólo se interesa por la verdad). En todo caso, pueden ser objeto de investigación de la psicología. Por el contrario, la ciencia, en tanto usuaria del lenguaje, sólo puede estar interesada en aquello que sólo tenga importancia en relación a la verdad. Qué deba tomarse en cuenta, entonces, está determinado en cierta forma por el segundo principio:

II) El segundo principio dice, siguiendo a Dummett, que "el significado de una palabra consiste, por completo, en la contribución que hace a la determinación precisa del acto lingüístico específico que puede efectuarse mediante la emisión de toda oración en la cual pueda aparecer la palabra" (19). Esto no implica que las palabras no tengan significado y que la mínima unidad significativa de un lenguaje sean los enunciados; por el contrario, Frege intenta mostrar que las palabras tienen significado, sólo que éste consiste en el papel que tienen en los

(18) Fundamentos de la aritmética, p. 113.

(19) Dummett, op. cit., p. 166. 
enunciados en que aparecen, enunciados cuyos sentidos están compuestos por el sentido de las palabras que los constituyen (20). Al remitir el significado de una palabra a su papel en la proposición se muestra que la vía de acceso a los significados en general está en estrecha relación con nuestra práctica lingüística.

III) La distinción, dada en el tercer principio, entre objeto y concepto (y además entre conceptos de primer y segundo nivel), se comprende a la luz de lo que Frege entendía por "objeto". Esta última noción es correlativa de lo que Frege llamaba un "nombre propio" (que pueden ser términos lógicamente simples o lo que Russell llamaba "descripciones definidas") y su importancia estaba ligada a la necesidad que tenía Frege de mostrar el análisis de la estructura de las oraciones que subyacía a la notación de variables y cuantificadores. El problema era a qué tipos de expresiones debe ir unido un cuantificador. Y la respuesta es que los cuantificadores pueden unirse a diferentes tipos de predicados (monádicos, diádicos, etc.). Pero para ello es necesario explicar la noción de "predicado", y la manera que tiene Frege de ofrecer dicha explicación es, partiendo de una oración completa, eliminar un nombre propio, con lo que se obtiene un predicado monádico (si se eliminan dos, se obtiene uno diádico, etc. ). En este proceso lo prioritario son los nombres propios, pues depende lo que se entienda por ellos, se entenderá por predicado, puesto que éste se obtiene eliminando nombres propios de una oración completa. Ahora bien, para Frege, un "objeto" es aquello a lo que se refiere un nombre propio, es su correlato objetivo. Dichos objetos pueden ser de los más variados tipos, a saber, tantos como tipos de nombres propios podamos reconocer. Por su parte, la noción de "concepto" (habría que decir de "función" en general, pues un concepto es un subconjunto del conjunto de las funciones, a saber, aquel cuyos valores para sus argumentos

(20) Es importante señalar, para no perder de vista la vinculación de las ideas de Frege sobre el lenguaje, que este segundo principio estaba destinado, en parte, a justificar el uso de "definiciones contextuales"- por ejemplo, de las ofrecidas en los axiomas de un sistema. 
son valores de verdad) es correlativa de la de "objeto". Una vez eliminado(s) un(os) nombre(s) propio(s) de una oración completa se obtiene un predicado, y la función (y como caso especial, el concepto) es el correlato objetivo de dicha expresión predicativa.

El tercer principio de los GA formula la necesidad de mantener estrictamente separadas dichas nociones, a saber, un objeto nunca puede ser un concepto $o$, dicho de otro modo, un predicado nunca puede remitir a un objeto y un nombre propio nunca puede remitir a una función. Esta concepción, ciertamente crucial en el sistema fregeano, traería serios problemas a Frege, en cuanto pronto se hallará en ciertas situaciones, generadas en parte por esta separación tajante entre función y objeto (y por tener un criterio lingüístico para identificar estas categorías), de no poder expresar todo lo que quisiera sin caer en paradojas, o sin verse en la desagradable situación de tener que decir que el lenguaje no sirve para expresar lo que debiera (21).

Con posterioridad a GA, Frege introdujo algunas importantes modificaciones en el terreno de sus ideas sobre el significado. La más conocida de ellas es la introducción de las nociones de "sentido" (Sinn) y "referencia" (Bedeutung). Son varias las razones que llevan a Frege a hacer el ajuste de conceptos que acompañó esta innovación, y una

(21) Para Frege, una expresión es un nombre propio si, en principio, no tiene hueoos que indiquen lugares a ser llenados; así, " $0+2=3^{n}$, no es un nombre propio sino un nombre de función (en este caso, de un concepto, pues su valor para los argumentos es un valor de verdad) y refiere, por lo tanto, a un concepto y no a un objeto. Supongamos que queremos ahora construir una expresión que refiera a ese mismo oncepto para decir algo de él, diremos: "el concepto del número que sumado a dos da tres"; pero esta expresión ya no tiene ningún hueco a ser llemado, por lo tanto es un nombre de objeto, así, obtenemos la paradoja de que el concepto del número que sumado a dos da tres es un objeto, y no un concepto como parece ser a primera vista; ver "Sobre concepto y objeton, en Escritos sobre semántica y, para una discusión de este tema que se ha dado en llamar el de los "indecibles" en Frege, ver de L. Valdivia Dounce, "Lo indecible en Frege", Rev. Análisis Filosófico, vol IV, № 1, mayo 1984 y, especialmente, de M.A. Preisser Rodríguez, "Los indecibles de Frege y su filosofia de la matemática", Rev. Análisis Filosófico, vol. IX, № 2, nov. 1989. 
de las más importantes es la de ofrecer una concepción adecuada de la noción de identidad (22).

El sentido de una expresión es la regla que rige el uso de la misma, y es, en todo caso, la principal parte del significado (tomando esta palabra en su significado más común) de una expresión. El referente no es una parte del significado de una expresión, sino aquello para cuya mención usamos un nombre (en el caso de un nombre), es decir, el "portador" de ese nombre. Así, dos nombres propios pueden tener distinto sentido pero idéntico referente; el mismo objeto puede tener dos nombres distintos con diferentes sentidos cada uno (por ejemplo, "2+2" y "4"). Un objeto es aquello a lo que se refiere un nombre propio.

Frege aplica análoga consideración a las expresiones predicativas; así, dice que un concepto (y, más generalmente, una función) es aquello a lo que se "refiere" una expresión predicativa, la cual deberá tener, tanto como los nombres propios, un sentido.

Pero no sólo los nombres propios y las expresiones predicativas son portadoras de sentido y referencia, también las oraciones lo son. Y lo sorprendente de esta situación es que una de las consecuencias de ello es que las oraciones deberán ser tratadas como nombres propios; en realidad, para Frege, las oraciones son nombres propios. Frege reconoce dos tipos básicos de expresiones: las que son completas o

(22) En BS Frege pensaba que la función del signo " $m$ " era simbolizar la identidad entre las expresiones entre las que se hallaba. Posteriormente cambiará de parecer, pues le parecía que si concebimos de ese modo la relación de identidad habrá que admitir que la verdad de una identidad como "la estrella matutina es idéntica a la estrella vespertina" dependerá de la filología o, en última instancia, de una convención, cuando se sabe que la única manera de establecer aquello es realizando observaciones astronómicas. Pero, aún si se dijera que la identidad es entre las expresiones, ¿qué es lo que se estaría diciendo? Que el contenido de la expresión de la izquierda es el mismo que el contenido de la de la derecha. Pero entonces, como sugieren M. y W. Kneale, la relación es entre "el contenido de la expresión "la estrella matutina"" y "el contenido de la expresión "la estrella vespertina"n. Y así se podría seguir. La solución adoptada por Frege es que la relación de identidad no es una relación diferente de la igualdad matemática, relación en la que, según Frege, el término de la izquierda refiere al mismo objeto al que refiere el de la derecha; sólo que ambos difieren en el modo en como refieren, en el sentido. 
saturadas (23) -nombres propios-, y las que no lo son -expresiones predicativas-. Las oraciones son expresiones completas, por eso Frege las considera nombres propios. Pero de ser así deben tener un referente. Este referente es, para Frege, un valor de verdad, es decir, en cada caso, lo verdadero o lo falso, los cuales para Frege son, por tanto, objetos. El "pensamiento" expresado por una oración (lo que Russell llamaría la "proposición") es para Frege su sentido. Si variamos las expresiones de una oración de modo que el referente de ellas no varíe, pensaba Frege, el referente de la oración no puede variar, mas sí puede hacerlo su sentido. Esta consideración (que es una aplicación del principio leibniziano que dice "eadem sunt quae sibi mutuo substitui possunt salva veritate") se complica sobremanera en los casos de palabras que tienen lo que se ha dado en llamar contextos oblicuos u opacos. Frege se ocupó de algunos problemas semánticos que surgen en relación a estos contextos y difícilmente pueda exagerarse la importancia de sus planteos (y sus soluciones) en relación a la semántica y la lógica filosófica, cuando se tiene en cuenta la magnitud que han cobrado estos contextos en teorizaciones posteriores.

\section{IV.- Conclusión}

De las múltiples áreas que manifiestan haber recibido el influjo de la obra de Frege, es quiza la filosofía del lenguaje la que lo hace en mayor medida. No están lejos de lo cierto quienes dicen que con Frege surge una corriente de pensamiento, a saber, aquella que hace de la filosofía del lenguaje su ámbito privilegiado de problematización.

Como afirma L.V. Villanueva (24), las actuales filosofías del lenguaje se ocupan de problemas que han sido tradicionalmente objeto

(23) La noción de "no saturación" de una expresión es una de las más oscuras de la semántica fregeana. Digamos sólo que una expresión es no saturada cuando se ha obtenido a partir de una oración (o de una descripción definida) gramaticalmente completa a la que se le han eliminado uno o varios nombres propios. Inversamente, si a esa expresion predicativa se le vuelven a insertar nombres propios en sus lugares vacíos, se obtiene nuevamente una expresión oompleta.

(24) A la búsqueda del significado, ed. Tecnos, Madrid, 1991, Introducción. 
de estudio de diversas ramas de la filosofía (teoría del conocimiento, metafísica, psicología filosófica, etc.) aunque no de modo sistemático; ahora, una gran cantidad de esas cuestiones aparecen estrechamente ligadas a la lógica. Efectivamente, el nacimiento de la filosofía del lenguaje moderna está en relación con el de la lógica simbólica, lo que explica el que se haya otorgado a ésta última un carácter básico en la formación de quienes se dedican a problemas relacionados con el lenguaje. El propósito de BS era introducir el máximo rigor posible en los métodos de prueba matemáticos, para lo cual Frege estimó necesaria la construcción de un lenguaje simbólico en el que pudieran llevarse a cabo las demostraciones con total garantía de que no se deslizasen errores debido al uso subrepticio de la intuición. Para realizar esto comprendió que era necesario efectuar previamente un examen de la estructura formal de los enunciados que componen las demostraciones, lo que a su vez le llevó a analizar el significado de los enunciados en términos del de sus componentes, esto es, se enfrentó a lo ineludible de un análisis de la estructura interna de éstos. Pero este trabajo parecía salirse de los límites de la lógica. La semántica del sistema lo llevó a enfrentarse con preguntas acerca de qué son las funciones, los conceptos, los objetos; también debió tratar de determinar claramente qué debe entenderse por "proposición verdadera", cómo debemos interpretar un enunciado de modo de determinar las condiciones en las cuáles es posible afirmar su verdad, etc.. Un ejemplo típico de este desplazamiento hacia la problemática semántica (desplazamiento no hacia un área preexistente, ya que en realidad abrió el campo a lo que luego pasó a llamarse semántica filosófica, etc.) es cómo la búsqueda de una definición de la identidad condujo sin remedio a Frege hacia al pregunta de si la identidad es una relación entre signos o entre designados, y luego, a la cuestión de qué significa exactamente que un signo designa o significa algo. En gran parte la teoría del sentido y la referencia es la respuesta que Frege intentó dar a estos problemas.

Es justamente a partir del cambio de perspectiva comentado que se ha desarrollado una de las líneas más importantes de la filosofía 
actual del lenguaje, precisamente en el espacio teórico, por así decir, que los desplazamientos de Frege fueron abriendo. Cabría preguntarse si es lícito afirmar que Frege fue un filósofo lingüístico (en el sentido en que se dice que lo son filósofos como Austin o Searle), si los problemas filosóficos que planteó Frege podrían expresarse como preguntas por el sentido de ciertas expresiones u oraciones. Sin duda cuestiones como qué significan los signos numéricos, o cuál es el análisis correcto de los enunciados que atribuyen números, o cuál es la función del signo de negación, etc., sugieren esta posición. Sin embargo, por ejemplo dentro de la filosofía de las matemáticas, bajo la necesidad de ofrecer algunos análisis de nociones matemáticas particulares, Frege estaba ciertamente interesado en dar una explicación general de la estructura del lenguaje, y con ella una teoría general del significado, al dar una explicación del sentido de las palabras particulares, cosa que justamente no intentan hacer aquellos filósofos. Por otro lado, la semántica fregeana clásica, por llamarla de algún modo, marca una posición opuesta a gran parte de la filosofía lingüística moderna, tanto de la escuela de Austin, como de la del segundo Wittgenstein, para quienes nuestras emisiones, aún cuando en términos gramaticales constituyen enunciados, pueden servir a muchos propósitos aparte del de expresar afirmaciones con determinadas condiciones de verdad, no siendo ya estas condiciones las que determinan el significado de los componentes del lenguaje. Frege no es un filósofo del lenguaje ordinario, al menos en relación a los lenguajes naturales respecto de los que sostuvo una desconfianza permanente en cuanto a sistematización se refiere. El hecho de que en el lenguaje natural pudieran hallarse nombres propios sin referencia, y oraciones sin un valor veritativo, constituía para Frege un defecto fatal del lenguaje natural, y marcaba la necesidad de la construcción de un lenguaje alternativo que eliminara estas deficiencias, al tiempo que evidenciaba la imposibilidad de efectuar una descripción completa de ese lenguaje y, por ende, de elaborar una teoría del significado para esos lenguajes.

Pero podríamos partir de la siguiente caracterización: "los problemas filosóficos son problemas esencialmente lingüísticos y su so- 
lución (o disolución) requiere bien una reforma del lenguaje o una elucidación más adecuada de su funcionamiento". Vista así, la filosofía lingüística aparece como un método de resolución de problemas, y entonces la figura de Frege aparece como central en esta tradición, junto a los nombres de Russell, Carnap y Wittgenstein.

Dummett defiende la tesis de que Frege llevó a cabo una revolución en filosofía analogable a la que se suele atribuir a Descartes. La revolución filosófica de Descartes consistió, según este autor, en haber dado por primera vez un lugar fundamental en la filosofía a la teoría del conocimiento. Desde Descartes hasta finales del siglo XIX podría decirse que la filosofía estuvo dominada por problemas epistemológicos: su aspiración central radicaría en determinar aquello hasta donde alcanza nuestro conocimiento, y en establecer los modos o métodos de justificar el mismo. La obra de Frege sería, según Dummett, la primera después de Descartes en donde se manifiesta el rechazo total de esta perspectiva. Aquí la epistemología ya no es prioritaria respecto a ninguna otra rama de la filosofía. Problemas como los de la posibilidad de adquirir conocimientos, o cómo adquirimos nuestras ideas, o el problema mismo de la naturaleza de las ideas, resultan para Frege secundarios. Ya no es el tratamiento de las condiciones de posibilidad del conocimiento lo que permitiría indagar acerca de la verdad de los enunciados con los cuales operamos, sino que es justamente el abordar cómo funcionan nuestros conceptos en la misma operación lógica-lingüística de la predicación lo que arrojará algo de luz sobre dicha verdad. Frege señaló que no es una teoría del conocimiento el camino que puede llevarnos a un correcto análisis de nuestros conceptos y, aún más, que es aquélla la que en última instancia depende de éste. La posesión de un concepto es algo que se manifiesta mediante el uso del lenguaje, de modo que el análisis de los conceptos no es algo distinto del análisis del funcionamiento del lenguaje. El problema no es determinar si es posible lograr conocimiento, sino mostrar las condiciones y procedimientos para lograrlo. Frege concibió que torias estas cuestiones dependen de la posesión de 
una lógica adecuada y de una correspondiente semántica y, consecuentemente, mantuvo como tarea central de la filosofía la búsqueda de una teoría del significado adecuada: la parte primera y básica de la filosofía pasaba a ser, así, la filosofía del lenguaje.

\section{RESUMEN}

En el presente artículo se realiza una presentación sucinta de la obra del filósofo alemán Gottlob Frege, a través de una reseña de su obra desde dos puntos de vista: I) su obra vista cronologicamente (|1) y II) su obra como una serie que va desde los problemas relacionados con los fundamentos de la matemática ( y su intento de resolución a través de la lógica) (|2), hasta una ampliación de dichos problemas más allá de las matemáticas (y los intentos de resolverlos mediante una semántica filosófica) (|3). Se concluye señalando la importancia de Frege para la actual filosofía del lenguaje. 